\title{
Especificidades do rendimento, aptidão e motivação escolares em alunos com dificuldades de aprendizagem
}

\author{
Fernando Oliveira Pereira \\ Escola Superior de Educação Almeida Garrett / Universidade Lusófona de LisboaLisboa - Portugal
}

\begin{abstract}
Resumo
As dificuldades de aprendizagem e outros factores específicos, internos e externos ao aluno, exercem influênciano rendimento escolar.Neste estudo foi aplicado o método de registo dos valores obtidos pelos alunos no desempenho de tarefas e domínio de conteúdos escolares e o de inquirição dos pais na avaliação dos filhos quanto à aptidão para aprender e à motivação para estudar. Foram encontradas diferenças estatisticamente significativas no rendimento escolar, na aptidão cognitiva e na motivação entre alunos com e sem dificuldades de aprendizagem. Nos primeiros, os valores obtidos nas três dimensões referidas - rendimento, aptidão e motivação escolares - são significativamente inferiores. Os alunos com dificuldades de aprendizagem, tendo por norma insuficiente rendimento, aptidão e motivação escolares, nalguns casos mantendose o défice de aptidão, mas aumentando a motivação e a dedicação ao estudo é possível alcançar rendimento escolar positivo, ainda que sofrível. Palavras-chave: Rendimento escolar; aptidão; motivação.
\end{abstract}

\section{Specificities of school performance, aptitude and motivation in students with learning difficulties}

\begin{abstract}
Learning difficulties andother specific factors of internal and external order to the student exert influence on school performance.In this study was applied the method of recording of the values obtained by the students on task performance and mastery of school contents and the inquiry of the parents in the assessment of children, as the ability to learn and motivation to study.On were found statistically significant differences in school performance, aptitudeand motivation to study, among students with and without learning difficulties. In the first one, was obtained values in the three dimensions mentioned - school performance, aptitude and motivation - are significantly lower. The students with learning difficulties, that normally have insufficient school performance, aptitude and motivation, in some cases keeping the aptitude deficit, but increasing themotivation and dedication to study is possible to achieve positive school performance, although poor.
\end{abstract}

Keywords: School performance; aptitude; motivation.

\section{Especificidades del rendimiento, aptitud y motivación escolares en alumnos con dificultades de aprendizaje}

\begin{abstract}
Resumen
Las dificultades de aprendizaje y otros factores específicos, internos y externos al alumno, ejercen influencia en el rendimiento escolar. En este estudio se aplicó el método de registro de los valores obtenidos por los alumnos en el desempeño de tareas y dominio de contenidos escolares y el de indagación de los padres en la evaluación de los hijos cuanto a la aptitud para aprender y a la motivación para estudiar. Se encontraron diferencias estadísticamente significativas en el rendimiento escolar, en la aptitud cognitiva y en la motivación entre alumnos con y sin dificultades de aprendizaje. En los primeros, los valores obtenidos en las tres dimensiones referidas - rendimiento, aptitud y motivación escolares - son significativamente inferiores. Los alumnos con dificultades de aprendizaje, teniendo por norma insuficiente rendimiento, aptitud y motivación escolares, en algunos casos manteniéndose el déficit de aptitud, pero aumentando la motivación y la dedicación al estudio es posible alcanzar rendimiento escolar positivo, aunque baja.
\end{abstract}

Palabras clave: Rendimiento escolar; aptitud; motivación. 


\section{Introdução}

O aluno como Ser humano é multifacetado, em cuja estrutura interior actua uma multiplicidade de factores, cada um deles exercendo maior ou menor grau na determinação dos seus comportamentos nas diversas situações da vida, em geral, e da actividade escolar e de aprendizagem, em particular.

O rendimento, de sucesso ou de insucesso, escolar ou educativo, resulta do comportamento e atitudes adoptados pelos alunos no processo de ensino-aprendizagem, podendo reflectir repercussões de diversos factores internos ou externos, cuja influência poderá variar entre o positivo e o negativo, o necessário e o desnecessário, o desejável e o indesejável, o adequado e o inadequado. Os factores poderão ser de natureza cognitiva, emocional, motivacional, volitiva, da personalidade, da interacção do aluno com a situação, da relação professor - aluno, aluno - alunos, da estrutura e organização familiar, escolar e da turma, entre outras.

Sendo as dificuldades de aprendizagem uma das causas do fraco rendimento escolar e consequente insucesso, suscita pertinência saber, em primeiro lugar, se existem verdadeiramente diferenças no rendimento alcançado por alunos com e sem as dificuldades referidas e, em segundo lugar, quais são alguns dos factores, de entre a multiplicidade existente, que provavelmente poderão estar na origem do fracasso escolar. Nestes dar-se-á maior relevo à aptidão para aprender e à motivação para estudar, reflectida na dedicação do aluno ao processo de estudo.

\section{Rendimento escolar dos alunos e avaliação da aprendizagem}

O rendimento escolar expressa-se por valores qualitativos que se traduzem em valores quantitativos equivalentes, assumindo quase sempre a forma numérica. Este tipo de rendimento pode numa escala contínua ocupar a posição convencionada como positiva ou na outra como negativa, sendo que os valores positivos da escala fazem-se corresponder ao conceito de sucesso escolar e os negativos ao conceito de insucesso escolar.

A problemática do sucesso e do insucesso escolar é relativamente recente, tendo, porventura, surgido com o alargamento do acesso à escola primária por toda a população que se encontra na idade considerada oportuna à frequência escolar (Benavente, 1990). Na Europa a explicação do fenómeno, desde a Segunda Guerra Mundial, assentou inicialmente na teoria dos "dotes", ou capacidades do aluno para aprender; seguiu-se a teoria das desvantagens socioculturais, ou seja do meio ambiente do qual o aluno é proveniente e, por fim, já nas últimas quatro décadas, centra-se mais nos mecanismos inerentes ao funcionamento operacional da própria escola. Portanto, na avaliação do sucesso ou insucesso não poderá ficar de fora a realidade histórica da instituição à qual pertence o aluno, até porque são apontadas diferenças entre aquilo que se entende por sucesso escolar e por sucesso educacional. Daí ser necessário estabelecer quais são os indicadores de sucesso escolar: taxas de promoção, notas, percentagens etc., sendo que variam em conformidade com os contextos. A mesma nota não corresponde às mesmas competências e competências iguais são avaliadas de forma diferente de instituição para instituição e até de classes. As notas resultam da comparação entre alunos que seguem o mesmo programa. Assim, um aluno médio poderá ser excelente numa turma fraca e medíocre numa turma forte. Uma escola só poderá avaliar aquilo que ensinou, ao passo que as avaliações externas medem aquilo que se reputa de ter sido ensinado em todas as escolas a partir de um currículo formal. Por isso, não se poderá confundir os conhecimentos e as competências efectivas de um aluno e o julgamento de excelência escolar do qual ele é objecto de avaliação (Perrenoud, 2003). Então, para que as comparações sejam objectivas e rigorosas é necessário que as avaliações assentem em critérios rigorosos, obedecendo a princípios de extensibilidade e universalidade.

Vários autores consideram que as causas do fracasso escolar são diferentes conforme sejam atribuídas por pais, alunos, professores ou o sistema educativo e que entre mitos e realidades ainda pairam muitas confusões. Por isso, partindo do pressuposto de que a realidade social transporta em si contradições, as quais tanto podem apelar à mudança como logo de seguida à permanência de certas relações sociais, sendo ela produzida historicamente, torna-se necessário e talvez imprescindível levar em linha de conta o contexto histórico, social, político e cultural em que essa realidade, quer do aluno, quer da escola, está inserida (Roazzi, \& Leandro, 1988; Nogueira, 1991, 1995; Almeida, Miranda,\& Guisande, 2008; Forgiarini,\& Silva, 2008; Lira, 2008).

$\mathrm{O}$ insucesso escolar pode ser visto de perspectivas diferenciadas. Os docentes tendem a atribui-lo à falta de bases, de motivação ou de capacidades dos alunos e também ao disfuncionamento das estruturas educativas, familiares e sociais. Os pais e a população consideram que os próprios professores também serão, em parte, responsáveis, devido à sua desmotivação e insuficiente preparação. Significa que o problema do insucesso escolar, maioritariamente, confina-se a questões de âmbito individual do aluno ou do docente. Maior operacionalidade poderá existir quando se remete o insucesso escolar para a questão da preparação científica e pedagógica dos docentes e do seu estatuto profissional; isto porque os docentes são os catalisadores do processo educativo. No entanto, tem-se vindo a centrar a questão do insucesso escolar nos problemas de política educativa e social (Roazzi, \& Almeida, 1988). A esta tendência reporta-se a perspectiva de Ana Benavente (1990) de que a escola deverá considerar as diferenças como diferenças e não como deficiências.

Muitos e variados são os factores que exercem influência no rendimento escolar dos alunos e, por conseguinte, no sucesso e insucesso escolares, começando pelos critérios de avaliação da aprendizagem efectivamente conseguida. Portanto, poder-se-á cair na questão das diferenças já mencionadas entre sucesso escolar e sucesso edu- 
cativo. No entanto, nesta investigação, assumir-se-á que há grau significativo de coincidência entre eles, sendo admitido que os resultados da avaliação escolar espelham o nível de aprendizagem alcançado pelos alunos em questão.

\section{As dificuldades de aprendizagem: rendimento, aptidão e motivação escolares}

O rendimento escolar resulta do equilíbrio e adequação da acção dos diversos factores de ordem interna e externa que exercem influência no processo de aprendizagem do aluno. Por conseguinte, as dificuldades de aprendizagem experimentadas pelo próprio aluno poderão ter repercussões negativas no rendimento escolar, sendo certo que as têm na aquisição e domínio de conhecimentos e que se manifestam essencialmente pelo insucesso escolar, mais concretamente insucesso educativo.

No Manual de Diagnóstico e Estatística de Transtornos Mentais (DSM - III) o problema das dificuldades de aprendizagem era visto como uma perturbação das aptidões escolares (Associação de Psiquiatria Americana [APA], 1980), sendo no DSM - IV tratado como perturbações da aprendizagem (APA, 1996).

Entretanto, não tem sido alcançado consenso quanto à definição da categoria "dificuldades de aprendizagem", porque aquelas que existem têm tido origem mais nas pressões e necessidades sociais e políticas do que propriamente nas bases científicas fundamentadas (Fonseca, 2004). A definição que maior consenso tem reunido é a proposta peloNational Joint Commitee on Learning Disabilities[NJCLD] (Comité Nacional Americano de Dificuldades de Aprendizagem). E é a seguinte:

Dificuldade de Aprendizagem é uma expressão genérica que refere um grupo heterogéneo de desordens manifestadas por dificuldades significativas na aquisição e no uso da compreensão auditiva, da fala, da leitura, da escrita e da matemática. Tais desordens são intrínsecas ao indivíduo, presumindo-se que são devidas a uma disfunção do sistema nervoso que pode ocorrer e manifestar-se durante toda a vida. Problemas na auto-regulação do comportamento, na atenção, na percepção e na interacção social podem coexistir com as dificuldades de aprendizagem. Apesar de as dificuldades de aprendizagem ocorrerem com outras deficiências (ex: deficiência sensorial, deficiência mental, distúrbio sócio-emocional) ou com influências extrínsecas (ex: diferenças culturais, insuficiente ou inadequada instrução pedagógica), elas não são o resultado de tais condições (NJCLD, 1988).

As dificuldades de aprendizagem devem ser abordadas no plano da interacção de factores com a finalidade de ajustar as condições internas do aluno às exigências das tarefas educacionais, ou seja, às condições externas da aprendizagem, às condições de ensino inerentes ao professor e ao sistema de ensino; aos processos de transmissão cultural. As teorias explicativas das dificuldades de aprendizagem têm-se preocupado mais com a descrição do que com a prescrição, fazendo do diagnóstico o fim em si mesmo, dando pouco ênfase à avaliação dinâmica e à maximização do potencial de aprendizagem do aluno (Fonseca, 2004). São várias as perspectivas de compreensão, interpretação e abordagem das dificuldades de aprendizagem, sendo que cada uma delas conceptualiza o problema com base num modelo unidimensional em que assume um dado aspecto como determinante do fenómeno: lesionais e cerebrais, percepto-motoras, da linguagem, neuropsicológicas, integracionistas.

No sistema escolar, onde o ensino e a aprendizagem são os processos principais, os alunos com dificuldades de aprendizagem ocupam uma faixa percentílica significativa, a par de outras categorias como a aprendizagem considerada normal dentro dos parâmetros estabelecidos, o insucesso escolar, o ensino especial e a disfunção cerebral mínima (Bos, \& Vaughn, 1988).

Nas perspectivas actuais de abordagem das dificuldades de aprendizagem, em particular no modelo interaccionista preconizado por alguns investigadores, o insucesso escolar não poderá ser totalmente explicado com base nas desordens implícitas nas condições internas do aprendente, porque outros factores interferem também: a despersonalização do programa escolar, o desinteresse do aluno e a falta de motivação para estudar (Adelman, 1971).

Daqui infere-se que o rendimento escolar dos alunos, concretamente o insucesso escolar, não tem origem exclusiva em perturbações nas condições internas e individuais que geram dificuldades de aprendizagem. $O$ insucesso escolar e educativo pode ter lugar em alunos com desenvolvimento normal das suas condições internas responsáveis pela aprendizagem, sendo consequência de factores, ainda que individuais, mais centrados no arco da interacção do sujeito com os diversos contextos do mundo envolvente.

O rendimento escolar na condição de sucesso e insucesso escolar e educativo poderá ser influenciado por factores da mais variada ordem e dimensão, desde que interfiram na funcionalidade psicossocial do aluno em interacção e relação com o mundo envolvente.

Há alunos cujo insucesso escolar está relacionado com problemas do âmbito das dificuldades de aprendizagem, as quais têm origem em particularidades das suas aptidões cognitivas, ou até de vivências emocionais na família ou com pares, mas também há alunos em que o insucesso escolar depende exclusivamente da sua dedicação ao estudo e da falta de motivação para tarefas escolares, porque noutras, por exemplo lúdicas, demonstra elevado rendimento. Na opinião de J. A. Bzuneck (2009), a responsabilidade pela desmotivação do aluno não poderá ser-lhe atribuída na totalidade, porque também existem problemas motivacionais que emergem das condições ambientais e da própria interacção do aluno com outros agentes - familiares, pares, professores. Embora muitas das vezes a desmotivação do aluno tem a ver com o facto deles mesmos trazerem para a sala de aula os seus interesses e valores individuais (Reeve, Deci,\& Ryan, 2004). 
É precisamente no processo evolutivo e de desenvolvimento das formas de conhecer, consequência de novas funções cognitivas e da especialização das mesmas, que o homo sapiens se vai transformando em homo discens; tornando possível e necessário novos processos cognitivos, cuja funcionalidade vai em muito para além daqueles que dotaram inicialmente o Ser humano no processo de evolução (Pozo, 2005).

Entretanto, os resultados da aprendizagem e consequentemente o rendimento escolar do aluno concreto poderão ser explicados por teorias explícitas diferentes, sendo que em cada uma delas também será diferente o aspecto psicológico determinante: inteligência e seus processos cognitivos envolvidos (Piaget, 1978; Sternberg, 1988), personalidade e suas componentes, principalmente emocionais e afectivas, envolvendo a auto-estima (Kelly, 1995; Norenzayan, Choi,\& Nisbett, 1999; Martini,\& Prette, 2005), estereótipos e crenças sociais (Rodrigo, Rodriguez,\& Marrero, 1993), motivação (Huertas,\& Agudo, 2003), processo de socialização, educação e aprendizagem (Kember, 1997; Pozo, \& cols., 1999; Máiquez, \& cols., 2000; Pérez Echevarría, \& cols., 2001).

Nesta investigação far-se-á relevância à influência de dois factores na aprendizagem: aptidão cognitiva e motivação do aluno para se dedicar ao estudo. No primeiro factor, relacionado com as diferenças individuais de âmbito cognitivo, passa pela abordagem baseada na capacidade intelectual do aluno, a qual também poderá ser especificada no plano das habilidades de natureza cognitivo-intelectual, podendo dominar no sujeito portador as acções dirigidas pela habilidade fluído-analítica ou pela habilidade verbal cristalizada, vindo de uma maneira ou de outra a repercutir-se na aprendizagem e consequentemente no rendimento escolar (Binet,\& Simon, 1916; Cattell, 1971; Horn, 1976; Carroll, 1992; Mestres,\& Goñi, 2000). No segundo factor - motivação do aluno para se dedicar ao estudo - reporta-se também às diferenças individuais, mas no âmbito dos aspectos inerentes à funcionalidade da personalidade, podendo exercerem influência positiva ou negativa, quer na aprendizagem, quer no rendimento escolares. Desempenham esta função: estilo cognitivo adoptado pelos alunos, ansiedade e expectativas de controlo nas situações de aprendizagem, auto-conceito e auto-estima, resultantes das avaliações que os alunos fazem de si e daquilo que efectivamente alcançaram, motivação, metas e objectivos e capacidade de auto-regulação do aluno no processo de estudo propriamente dito. É precisamente este último aspecto psicológico que envolve a motivação do aluno para estudar, sendo habitualmente definida de forma simplificada como estado interior, cujas funções mais relevantes são a estimulação, a direcção e a manutenção do comportamento, podendo, assim, ser aplicada aos mais variados tipos de questões (Graham, 1996). Daí que S. E. R. Guimarães (2001), S. E. R. Guimarães e E. Boruchovitch (2004) tivessem referido que a promoção da motivação do aluno para a actividade de aprendizagem escolar deve passar pelo envolvimento e esforço da comunidade académica, especialmente dos professores, na criação de um sistema de interacção promotor da autonomia do aluno, dando-
-Ihe mais oportunidades e fazendo-o ser mais responsável pelas consequências dos seus actos. Entretanto, adquire importância a compreensão da motivação como intrínseca e extrínseca, cuja finalidade consiste na objectivação da verdadeira origem de certos comportamentos dos alunos (Sprinthall, \& Sprinthall, 1997; Woolfolk, 2000; Mestres, \& Goñi, 2000). Contudo, a motivação conceptualizada como tem sido no âmbito da dicotomia intrínseca - extrínseca é redutora,em particular quando pretende explicar a enorme variedade de metas e objectivos perseguidos pelos alunos nas situações de aprendizagem (Tapia, 1991).

A motivação intrínseca tem sido vista na condição de traços pessoais individuais e de origem interna. Caracteriza pessoas endogenamente motivadas que perseguem objectivos internamente concebidos. A motivação extrínseca tem localização exógena nos ambientes envolventes: recompensas, pressão social, punições, prémios. Neste plano a motivação é mais um estado temporal activado enquanto existir a possibilidade de obtenção de algo que ainda não é seu, mas que poderá conquistar. Habitualmente as inferências acerca da motivação dos alunos eram vistas num plano de descontinuidade, atribuindo a origem dos estímulos desencadeantes da activação para a aprendizagem ora a factores internos, ora a factores externos; daí a imensidão do campo motivacional ter sido resumida dicotomicamente a dois tipos de motivação - extrínseca e intrínseca.

Com a finalidade de superar as incongruências de explicação desta tipologia das motivações, nos últimos tempos foram vários os autores que aderiram à teoria da autodeterminação da motivação, a qual apresenta uma perspectiva inovadora de interpretar a motivação como determinada num continuum ininterrupto, conferindo-Ihe continuidade e também apresentando graus de activação em conformidade com onível de interiorização das estruturas ou estilos de regulação da actividade (Reeve, Deci, \& Ryan, 2004; Gagné, \& Deci, 2005; Ryan \& Deci, 2007).

$\mathrm{Na}$ teoria da autodeterminação a motivação tem origem em três necessidades psicológicas básicas - autonomia, competência, vinculação - que impulsionam o ser humano a procurar alcançar a sua satisfação nas condições ambientais de âmbito sociocultural reinante no meio que o rodeia e onde as situações de interacção são operacionalizadas (Reeve, \& cols., 2004). A teoria da autodeterminação tem vindo a ser aplicada frequentemente ao estudo da motivação na aprendizagem escolar em que são indicados num contínuum seis tipos de motivação que variam qualitativamente conforme o predomínio da internalização das regulações externas do comportamento (Leal, Miranda,\& Carmo, 2013).

A teoria da autodeterminação da motivação opera com base em princípios de avaliação, aos quais se reporta a vasta gama das diferentes manifestações motivacionais, podendo estas ter implicação no processo de ensino-aprendizagem. A própria cultura reinante no país, no sistema escolar, no meio ambiente em que o aluno se encontra inserido poderão exercer influência sobre a motivação (Rothstein-Fisch, \& Trumbull, 2008; Trumbull, \& Rothstein-Fisch, 2011). Segundo Siqueira e Wechsler (2006) actualmente a motiva- 
ção não é vista apenas como pré-condição de activação da tarefa ou da actividade, demonstrando existir reciprocidade na relação de inter-influência entre a motivação e a aprendizagem; ou seja, quer uma, quer a outra, podem influir uma na outra.

No modelo da teoria da autodeterminação a motivação é representada num continuum onde se encontram inscritos seis tipos, cuja diferenciação qualitativa varia em conformidade com o grau de internalização das regulações externas do comportamento. A motivação opera no continuum em sentido unidireccional em dois planos: da inexistência para a existência e da exterioridade para a interioridade. Consequentemente, o primeiro tipo é designado de "desmotivação" ou "amotivação", caracterizando-se pela ausência de motivação e, por conseguinte, pela ausência de regulação intencional. O segundo, terceiro, quarto e quinto tipos reportam-se à extensibilidade referente à chamada motivação extrínseca, subentendendo-se haver em cada um deles graus de activação diferenciados com correspondência a tipos ou estilos de regulação também diferentes. Então ter-se-á a seguinte correspondência tipo de motivação estilo de regulação: controlado - externo; moderadamente controlado - introjectado; moderadamente autónomo - identificado; autónomo - integrado. O sexto tipo representa a motivação intrínseca propriamente dita, ou seja a motivação autónoma por inerência, em que a regulação faz parte da própria essência funcional do sujeito, revelando o verdadeiro interesse e prazer do aluno pela tarefa que está a realizar (Gagné, \& Deci, 2005; Ryan, \& Deci, 2007).

No entanto, em consonância com a metodologia adoptada na investigação, assume relevância a especificidade e a compreensão do modelo teórico de atribuição. Nos alunos há tendência destes a fazer atribuições de causalidade do sucesso e do fracasso à variável "esforço" e do insucesso à variável "falta de método adequado de estudo". Entretanto, à medida que os alunos avançam na escolaridade passam a valorizar mais a atribuição do sucesso às suas bases ou conhecimentos e o insucesso à falta de esforço e de método de estudo. Quanto ao género, o masculino atribui o sucesso às suas capacidades e o feminino ao esforço e às suas bases ou conhecimentos (Almeida, Miranda, \& Guisande, 2008).

Jere Brophy (1988) caracteriza a motivação para aprender como a tendência que o aluno tem para atribuir significado e valor às actividades académicas, procurando delas obter os benefícios pretendidos. Ao que parece, os objectivos, as necessidades e as crenças dos alunos são aspectos que directa ou indirectamente se encontram envolvidos na motivação para aprender; sendo que objectivamente se dirigirá para aquilo a que ele atribui importância, significado, valor.

Nestas abordagens o enfoque incidiu sobre as atribuições de causalidade que o próprio sujeito da acção, ou seja o aluno, considera serem responsáveis pelo seu sucesso ou insucesso na execução das tarefas ou realização das actividades. Este modelo emana directamente da teoria intra-pessoal de atribuição, cuja interpretação consiste em ser o próprio aluno a atribuir as causas do seu êxito ou fracasso (Weiner, 1984). Entretanto, o mesmo autor criou mais recentemente a teoria interpessoal de atribuição, ou até da motivação, na qual as atribuições são elaboradas não pelo próprio sujeito da acção, mas por outras pessoas, embora com papel significante na vida do aluno que obteve sucesso ou fracasso - pais, amigos, pares, familiares, professores. Então, a teoria interpessoal assenta nas inferências acerca de causas controláveis ou incontroláveis dos comportamentos de sucesso ou fracasso de outros (Weiner, 2000, 2004).

Por conseguinte, decorrendo da reflexão e compreensão dos conteúdos, acima expostos, foi tomada a decisão de investigar, em alunos referenciados pela escola como tendo dificuldades de aprendizagem, com base na avaliação que os seus pais fazem de duas prováveis causas do insucesso - aptidão cognitiva para aprender e motivação para estudar -, que influências têm no seu rendimento escolar.

\section{Método}

\section{Amostra}

A amostra desta investigação é constituída por 275 alunos de ambos os géneros, havendo mais do masculino que do feminino, referenciados pelas escolas que frequentam por revelarem dificuldades de aprendizagem dos conteúdos escolares; sendo confirmado o diagnóstico na consulta de psicologia onde são seguidos no serviço de pediatria do sistema hospitalar. Estes alunos encontram-se distribuídos por diversas idades compreendidas entre os 7 e os 15 anos. Então são: com 7 anos (85 - 96 meses) - 35 alunos; 8 anos (97 - 108 meses) - 40 alunos; 9 anos (109 - 120 meses) 50 alunos; 10 anos (121 - 132 meses) - 45 alunos; 11 anos (133 - 144 meses) - 30 alunos; 12 anos (145 - 156 meses) - 25 alunos; 13 anos (157 - 168 meses) - 25 alunos; 14 anos (169 - 180 meses) - 25 alunos. Uma parte significativa destes alunos - metade - frequentava o $1^{\circ}$ ciclo e a outra parte, a outra metade, frequentava o $2^{\circ}$ e o $3^{\circ}$ ciclo do ensino básico.

Paralelamente foi constituído um contingente de 275 alunos saudáveis que não experimentavam qualquer dificuldade de aprendizagem e que apresentavam correspondência identitária quanto às características etárias, de género e de condição socioeconómica. Da mesma forma este contingente foi distribuído por grupos idênticos, quanto à dimensão e características sócio-demográficas, aos, já acima apresentados, que revelavam dificuldades de aprendizagem.

Em concordância com os dois contingentes de alunos apresentados foram formados também dois contingentes de pais, constituídos pelos encarregados de educação dos alunos com a finalidade de responderem aos questionários que faziam parte do processo de recolha de dados. 


\section{Metodologia da investigação}

Partindo do objectivo principal que consiste em investigar, por um lado, as diferenças de rendimento escolar entre alunos com e sem dificuldades de aprendizagem e, por outro, quais os factores que se encontram na base do fraco rendimento escolar, foram colocadas várias hipóteses:

HO - Não existem diferenças significativas no rendimento escolar entre os contingentes de alunos com e sem dificuldades de aprendizagem, nem nos factores interferentes.

H1 - Há diferenças significativas na expressão do rendimento escolar entre os dois contingentes de alunos: com e sem dificuldades de aprendizagem.

$\mathrm{H} 2$ - O rendimento escolar é significativamente inferior nos alunos com diagnóstico de dificuldades de aprendizagem face àquele obtido pelos alunos que não apresentaram dificuldades.

$\mathrm{H} 3$ - Os alunos referenciados com dificuldades de aprendizagem denotam factores de aptidão para aprender e de dedicação ao estudo das matérias escolares fracos com certo grau de insuficiência face ao exigido.

Com base nestas hipóteses formulam-se as seguintes questões de investigação:

1. Existirão diferenças significativas no rendimento escolar e nos factores de aptidão para aprender e motivação para estudar entre os alunos identificados com e sem dificuldades de aprendizagem?

2. Em qual dos contingentes, com ou sem dificuldades de aprendizagem, os valores obtidos no rendimento escolar, na aptidão cognitiva para aprender e na dedicação motivacional ao estudo, dos alunos, é menos expressivo, e porquê?

\section{Delineamento da investigação}

Em primeiro lugar procedeu-se ao estabelecimento e consequente confirmação do diagnóstico "dificuldades de aprendizagem": existência ou ausência. De seguida, com base no critério de existência ou ausência de dificuldades de aprendizagem, foram constituídos dois contingentes de alunos.

Formados os dois contingentes de alunos, com e sem dificuldades de aprendizagem, foi solicitado aos seus pais, ou encarregados de educação, um por um, individualmente, o preenchimento dos respectivos questionários adoptados nesta investigação, respeitantes às notas obtidas pelos seus educandos nos três períodos escolares dos anos transacto e actual, sendo especificadas as suas avaliações na entrevista psicopedagógica.

Terminada a recolha de dados deu-se início ao seu tratamento estatístico, norteado metodologicamente pelas questões colocadas nesta investigação, as quais determinaram a selecção dos critérios e métodos estatísticos mais consonantes à obtenção de respostas que permitam fazer conclusões objectivadas. Daí que se tivesse optado pela comparabilidade dos resultados entre contingentes, aplicando o critério $\mathrm{t}$ - Student, cuja finalidade foi encontrar diferenças específicas no funcionamento psico-pedagógico dos alunos, responsáveis pelo rendimento escolar.

\section{Instrumentos metodológicos de recolha de dados}

1. Entrevista clínico-psicológica orientada para o diagnóstico especificado e de confirmação, ou não, da existência de dificuldades de aprendizagem nos alunos referenciados e identificados pela escola como tal, tendo por finalidade manter ou excluir esses alunos do contingente ao qual foram dirigidos.

2. Questionário sobre características sócio-demográficas e escolares do aluno: das primeiras faziam parte a identificação do aluno quanto ao género, à idade e à condição familiar; das segundas, o ano de frequência escolar actual, a frequência de retenções e em que ano escolar tiveram lugar.

3. Questionário de rendimento escolar. Este apresentado em forma de quadro, ou grelha, de registos, no qual eram registadas as notas, obtidas pelo aluno, numa escala de 0 a 5 valores, nos três períodos escolares referentes ao ano actual de frequência e ao ano transacto.

4. Questionário de atribuição de competências e de causas dirigido aos pais do aluno, ou ao encarregado de educação. Estes caracterizavam os alunos, numa escala qualitativa, de mau, medíocre, razoável, bom ou excelente, sendo posteriormente atribuídos, pelo investigador, valores numéricos correspondentes - 0, 1, 2, 3, 4, 5 - à escala do sistema escolar, referente ao rendimento escolar. Os pais, ou encarregados de educação do aluno, eram convidados a registar, com base na sua percepção, qual o nível de aptidão cognitiva para aprender as matérias escolares pelo aluno concreto, que eles tão bem conhecem. Também, no mesmo formato de questão, qual o grau de motivação do aluno para aprender, baseando-se naquilo que dele conhecem quanto à sua aplicação e dedicação ao estudo.

É oportuno esclarecer que nesta investigação sobre a motivação para estudar a ênfase foi focada nalgumas manifestações motivacionais das atitudes e do comportamento do aluno - a aplicação e a dedicação ao processo de estudo. Contudo, tendo a noção que a motivação é um conceito que abrange maior extensibilidade e profundidade do que a simplicidade psicossocial da aplicação e dedicação ao estudo, esta não deixa de ser uma manifestação motivacional na sua essência; por isso, com todas as contingências que daí advêm, manter-se-á na discussão o conceito de motivação, por maior familiaridade e comodidade, mas procurando especificar no texto, quando oportuno, que se reporta ao fe- 
nómeno de dedicação ao processo de estudo e preparação das matérias para os testes.

\section{Resultados}

Nesta seção apenas será exposta a tabela referente à comparação da expressividade do rendimento, da aptidão e da motivação escolares entre alunos com e sem dificuldades de aprendizagem, reportados integralmente ao grupo de idades que oscilam entre os 7 e os 15 anos. Embora na investigação tenha sido realizada a comparação entre os grupos de alunos acima referidos por idades de forma independente: 7, 8, 9, 10, 11, 12, 13, 14 e 15 anos. A decisão de apresentar apenas os resultados obtidos no período etário 7 - 15 anos, integralmente, fundamenta-se na análise prévia realizada individualmente por idades; tendo-se verificado que as diferenças estatisticamente significativas são evidentes e idênticas de idade para idade e que o factor preponderante na variação das diferenças não é a idade, mas a existência ou ausência de dificuldades de aprendizagem.

A tabela 1 mostra que todas as componentes submetidas à investigação revelam diferenças estatisticamente significativas ao nível $p<0.000$ e maior grau de expressi- vidade, no que respeita ao rendimento escolar, à aptidão para aprender, à motivação para estudar, ao ano escolar de frequência, no contingente de alunos em que as dificuldades de aprendizagem estão ausentes, ao mesmo tempo que têm menor quantidade de retenções escolares e nula a existência de adaptações curriculares.

A diferença numérica revelada na categoria "ano de frequência escolar" evidencia a possibilidade de inferir, com certa margem de segurança, que os alunos onde imperam as dificuldades de aprendizagem encontrar-se-ão a frequentar anos escolares inferiores àquele que a sua idade cronológica permitiria e recomendaria. Facto corroborado pela diferença significativa de maior quantidade de retenções escolares neste contingente de alunos, sendo também indicador confirmativo da existência de dificuldades de aprendizagem a necessidade que houve de implementação de adaptações curriculares; saindo reforçada a ideia pela inexistência deste tipo de adaptações, ou adequações, no contingente de alunos que não apresenta dificuldades.

Quanto à categoria "rendimento escolar", seja o global ou o específico em áreas como a "língua portuguesa", "matemática", "estudo do meio/ciências naturais" as diferenças de expressividade são estatisticamente significativas e a nível bastante elevado. A escala numérica de atribuição

Tabela 1. Comparabilidade do rendimento, da aptidão e da motivação escolares entre alunos com e sem dificuldades de aprendizagem.

\begin{tabular}{|c|c|c|c|c|c|c|c|c|}
\hline \multirow{2}{*}{$\begin{array}{l}\text { Grupos } \\
\text { Escalas }\end{array}$} & \multicolumn{2}{|c|}{$\begin{array}{l}\text { Alunos } \\
\text { Dificuldades } \\
\text { Aprendizagem }\end{array}$} & $\begin{array}{r}\text { com } \\
\text { de }\end{array}$ & \multicolumn{2}{|c|}{$\begin{array}{l}\text { Alunos } \\
\text { Dificuldades } \\
\text { Aprendizagem }\end{array}$} & $\begin{array}{r}\text { sem } \\
\text { de }\end{array}$ & \multirow[t]{2}{*}{$\mathrm{t}$} & \multirow[t]{2}{*}{ Sig. } \\
\hline & M & $\mathrm{DP}$ & & $M$ & DP & & & \\
\hline Ano de frequência escolar & 4,24 & 2,00 & & 4,91 & 2,12 & & $-9,59$ & $p<0,000$ \\
\hline $\begin{array}{l}\text { Retenções escolares } \\
\text { (quantidade) }\end{array}$ & 0,75 & 0,44 & & 0,18 & 0,39 & & 16,52 & $p<0,000$ \\
\hline $\begin{array}{l}\text { Adaptações curriculares } \\
\text { aplicadas }\end{array}$ & 0,18 & 0,39 & & 0,00 & 0,00 & & 7,80 & $p<0,000$ \\
\hline Rendimento escolar global & 2,57 & 0,40 & & 3,62 & 0,68 & & $-22,88$ & $p<0,000$ \\
\hline $\begin{array}{l}\text { Rendimento a Língua } \\
\text { Portuguesa }\end{array}$ & 2,37 & 0,52 & & 3,54 & 0,69 & & $-21,71$ & $p<0,000$ \\
\hline Rendimento a Matemática & 2,58 & 0,53 & & 3,66 & 0,72 & & $-21,71$ & $p<0,000$ \\
\hline $\begin{array}{l}\text { Rendimento a Estudo do } \\
\text { Meio / Ciências Naturais }\end{array}$ & 2,82 & 0,53 & & 3,68 & 0,80 & & $-16,41$ & $p<0,000$ \\
\hline $\begin{array}{l}\text { Aptidão para aprender } \\
\text { (competência cognitiva) }\end{array}$ & 3,00 & 0,54 & & 3,73 & 0,59 & & $-16,60$ & $p<0,000$ \\
\hline $\begin{array}{l}\text { Motivação para estudar } \\
\text { (dedicação ao estudo) }\end{array}$ & 2,18 & 0,83 & & 3,36 & 0,96 & & $-16,00$ & $p<0,000$ \\
\hline
\end{tabular}


de valores é aquela que se utiliza no sistema escolar, no intervalo 0 - 5 valores. Na prática constitui-se dos valores: 2 , 3,4 e 5, representando o 2 todo o espaço relacionado com a avaliação negativa.

Neste âmbito verifica-se que a média de valores apurada para o contingente de alunos com dificuldades de aprendizagem, quanto ao rendimento escolar global, mas também no específico, separadamente para as áreas da Língua Portuguesa, da Matemática e do Estudo do Meio/ Ciências da Natureza, encontra reflexo no campo reportado ao valor 2 , no intervalo [2,3 - 2,8], sendo que no contingente de alunos sem dificuldades de aprendizagem se reporta ao valor 3 , no intervalo $[3,5-3,68]$. Valores que explicam a tendência dos alunos com dificuldades de aprendizagem para obterem classificações negativas, nas avaliações no final dos períodos e no final do ano escolar, caracterizando-os de fraco rendimento escolar, ou negativo, e consequentemente de insucesso escolar. Contrariamente, nos alunos que não apresentaram dificuldades de aprendizagem a tendência foi para obterem resultados que denotam bom rendimento escolar, positivo, tendo, em consequência disso, sucesso escolar.

A tendência verificada no rendimento escolar dos alunos com e sem dificuldades de aprendizagem, resultante das avaliações realizadas pelos professores face ao grau de aquisição e domínio dos conteúdos escolares pelos respectivos alunos é mantida na avaliação que os pais fazem dos seus filhos quanto à capacidade ou aptidão que eles têm para aprender os conteúdos escolares e também quanto à motivação para estudar, ou seja, a dedicação ao estudo das matérias em casa.

Os valores atribuídos à capacidade dos filhos para aprender, ainda que inferior no contingente das dificuldades de aprendizagem comparativamente ao contingente de alunos sem dificuldades, embora no limiar mínimo, são tendencialmente de índole positiva. De qualquer modo não se descurará a evidência do contingente de alunos criteriosamente categorizado de terem dificuldades de aprendizagem quanto à capacidade ou aptidão para aprender, segundo a avaliação dos seus pais, poder efectivamente constituir-se de dois grupos de alunos: um que a aptidão cognitiva e intelectual é mesmo deficitária para aprender e dominar convenientemente os conteúdos escolares e os pais também não têm essas dúvidas, atribuindo mesmo valores negativos na avaliação que fizeram da categoria; outro, em que a aptidão não é verdadeiramente deficitária, até os próprios professores chegam a considerar isso, e os pais também avaliam os seus filhos como tendo capacidade e inteligência, ainda que não seja brilhante, mas suficiente, e a necessária, para aprender e dominar os conteúdos escolares. Isto é o que se pode inferir da interpretação baseada nos valores estatísticos obtidos, atendendo à flutuação do desvio padrão, fazendo com que os valores atribuídos pelos pais na avaliação estejam distribuídos, ao que parece com índice de homogeneidade significativo, parte na área negativa e parte na área positiva, no que respeita ao contingente com dificuldades de aprendizagem. Já que no contingente dos alunos sem dificuldades de aprendizagem, mesmo atendendo à flutuação do desvio padrão, os valores atribuídos pelos pais à capacidade dos seus filhos para aprenderem quedaram-se todos no campo positivo.

Os valores atribuídos pelos pais à motivação dos fiIhos para estudar, correspondente à dedicação e aplicação ao estudo das matérias escolares em casa, no contingente de alunos com dificuldades de aprendizagem são na totalidade, ou quase, negativos, recaindo de forma absoluta tendencialmente no campo referente à negatividade do grau, ou nível, motivacional. Assim o demonstra a flutuação do desvio padrão que mantém estatisticamente os valores respeitantes ao nível motivacional e ao grau de dedicação e aplicação destes alunos ao estudo sempre no campo do défice de estimulação interior para a impulsão da actividade comportamental específica do contexto de aprendizagem escolar.

\section{Discussão}

No que concerne à caracterização sócio-demográfica e da condição da frequência escolar dos alunos com dificuldades de aprendizagem ficou demonstrado que neste contingente submetido à investigação a tendência é para estes alunos apresentarem idade cronológica mais avançada, ano de frequência escolar inferior, mais retenções escolares e adaptações curriculares relativamente àquilo que se verifica em alunos que não se incluem, por razões óbvias, na categoria de dificuldades de aprendizagem.

O rendimento escolar do contingente de alunos com dificuldades de aprendizagem também é demonstrativo da existência dessas dificuldades, sendo absolutamente visível na tendência predominante para se quedarem na faixa representativa das avaliações negativas; tanto na média geral do conjunto de avaliações, como nos resultados alcançados em cada unidade curricular, separadamente.

Entretanto, as componentes referentes à estrutura psicológica dos alunos, tendo em consideração as avaliações que delas foram feitas, não são tão peremptoriamente demonstrativas da existência, neste contingente de alunos, de verdadeiras dificuldades de aprendizagem. Embora seja evidente que grande parte dos alunos constituintes do contingente conotado com as dificuldades de aprendizagem tenha défices significativos na capacidade, ou aptidão, para aprender; há uma parte de alunos que não tem propriamente falta de capacidade cognitiva para dominar os conteúdos escolares, mas tal como os anteriores alcançam valores negativos no rendimento escolar. Para estes últimos o insucesso escolar radica provavelmente mais na fraca motivação para estudar, traduzida pela deficitária dedicação ao processo de estudo.

Naqueles alunos em que as dificuldades de aprendizagem resultam verdadeiramente do défice de capacidade ou aptidão para aprender a explicação é corroborada por vários autores, baseando-se essencialmente na deficitária funcionalidade cognitiva e nos fracos recursos da inteligência (Piaget, 1978; Sternberg, 1988; Fonseca, 2004). 
Nos outrosalunos que não tinham propriamente défice de capacidade ou aptidão para aprender, mas sendo mal sucedidos no rendimento escolar devido a factores motivacionais relacionados com fraco envolvimento em tarefas escolares, particularmente a reduzida dedicação ao estudo, provavelmente vão transitando de ano com resultados negativos sempre numa ou noutra unidade curricular; ao que parece acabam por ter sucesso escolar, mas quedam-se as dúvidas se alcançaram sucesso educativo (Perrenoud, 2003). Contudo, os valores resultantes da avaliação feita à operacionalização activa da componente motivacional indiciam tendencialmente que todos, ou quase todos, os alunos do contingente das dificuldades de aprendizagem denotam fracos índices motivacionais e de interesse pelo processo de estudo, manifestando-se essencialmente na pouca dedicação ao estudo dos conteúdos escolares.

O facto dos alunos com dificuldades de aprendizagem por causa do défice de capacidade ou aptidão para aprender também apresentarem frequentemente falta de motivação para estudar, quando com recurso a índices de maior aplicação e dedicação ao processo de estudo poderiam influenciar positivamente o seu rendimento, fundamenta-se na existência de reciprocidade entre a motivação e a aprendizagem (Siqueira, \& Wechsler, 2006), sendo unânime que o nível motivacional influencia o nível de aprendizagem, também é plausível que resultados de aprendizagem negativos, apesar do esforço dispendido pelo aluno, conduzam à perda ou redução do interesse por continuar a dedicar-se às tarefas com a mesma intencionalidade, em vão.

Então, relacionando o défice motivacional para estudar com a aptidão cognitiva para aprender, no contingente das dificuldades de aprendizagem, no grupo em que a aptidão é considerada suficiente para o desempenho da actividade em conformidade com as metas e os objectivos da escolaridade e consequentemente a alcançar rendimento escolar positivo, poderá efectivamente conduzir, sendo que conduz com alguma frequência, à diminuição de grau ou nível de rendimento, recaindo este, a maior parte das vezes, no campo negativo. Neste caso, a causa é fundamentalmente a fraca motivação para estudar e, por consequência, a falta de dedicação ao processo de estudo. A explicação deste fenómeno é perfeitamente fundamentada recorrendo à teoria de autodeterminação da motivação no continuum, dominando nestes alunos o tipo de desmotivação em que o estilo de regulação do comportamento não é intencional, ou, na melhor das hipóteses, o tipo de motivação controlada com predominância do estilo de regulação externo (Gagné, \& Deci, 2005; Ryan, \& Deci, 2007; Leal, Miranda, \& Carmo, 2013).

Quando a aptidão cognitiva para aprender é considerada pelos pais deficitária e a motivação para estudar também, o rendimento escolar, apesar de ser impreterivelmente negativo, sai ainda mais agravado do que eventualmente sairia se houvesse interesse, motivação e dedicação ao estudo. Por outro lado, a consciência que o aluno tem das suas limitações cognitivas para aprender conduz à redução da sua auto-estima e auto-conceito, podendo, na condição de mecanismo de defesa do seu Ego e da sua integridade psicossocial, impelir ao desinteresse e desmotivação para estudar, materializadas nas diversas formas comportamentais que o aluno usa para evitar aplicar-se e dedicar-se ao processo de estudo.

É talvez esta a forma que o aluno em questão encontrou, consciente ou inconscientemente, para mostrar que não aprende porque não quer, e não porque tenha falta de capacidade intelectual. Do ponto de vista psicológico, social e culturalmente é mais fácil e aceitável, para o sujeito, atribuir o insucesso ao seu querer, ou não querer, ao desinteresse, do que à falta de capacidades, aptidões, mais grave à sua falta de inteligência. Esta, para ele, parecerá ser vergonhoso aos olhos dos outros. Poderá entender isto como sinónimo de ser considerado pelos outros como incompetente noutras áreas de interacção e relacionamento social e interpessoal; por isso, a melhor forma será mascarar, ou negar, o óbvio. Afirmações interpretativas que podem ser corroboradas pela teoria intra-pessoal da atribuição das causas que motivam os seus próprios comportamentos (Weiner, 1984; Almeida, Miranda, \& Guisande, 2008), sendo as causas reais daquilo que aconteceu relativamente ao sucesso ou insucesso na tarefa outras. Daí que, com base na teoria interpessoal, as atribuições de causalidade elaboradas por outras pessoas - pais, pares, familiares, professores - encontrem outras causas, ou motivos, responsáveis pelas actuações ou comportamentos dos alunos, aquando da execução de tarefas escolares com sucesso ou com insucesso (Weiner, 2000, 2004).

Entretanto, no contingente sem dificuldades de aprendizagem, no que respeita à aptidão cognitiva para aprender a flutuação do desvio padrão mantém sempre os valores da avaliação dos pais ao nível da positividade, no campo da competência. Já no que respeita à motivação para estudar as oscilações produzidas pela flutuação do desvio padrão são bastante contraditórias; sendo que há uma percentagem bastante elevada de alunos em que a motivação, ou a própria dedicação, recolhe índices negativos. Significa que os alunos deste contingente só vêem o seu rendimento escolar afectado em termos de redução para graus abaixo daqueles para que as suas reais capacidades permitiriam. Mas a redução do nível de rendimento escolar não é suficiente para significar insucesso escolar. Na maior parte das vezes estes alunos vão transitando de ano, embora com negativas aqui e ali, nesta ou naquela unidade curricular, havendo quase sempre sucesso escolar.

Contudo, numa abordagem mais profunda e concisa surgem sérias dúvidas se estes alunos alcançam verdadeiramente sucesso educativo, na medida em que este corresponde à aquisição e domínio efectivos dos conteúdos escolares, marcando positivamente o desenvolvimento e a evolução produzidos na estrutura do conhecimento do aluno, tendo ao mesmo tempo repercussões positivas no desenvolvimento do sujeito, como pessoa e cidadão, aquando da aplicação desses conhecimentos às actividades que vai realizando na sua vida. O sucesso escolar apenas se reporta ao facto de o sujeito na condição de aluno ter tran- 
sitado os anos respeitantes à escolaridade e finalizada esta com sucesso, ou seja obtendo notas positivas, as quais são indicadores numéricos e quantitativos que revela em que medida o aluno superou as metas propostas pelo sistema; embora, tecnicamente, as notas devam reflectir a caracterização qualitativa do desempenho. Então, e se houvesse elevação do nível de exigências do sistema escolar, quanto ao grau de aquisição e domínio dos conteúdos ministrados, continuaria a ter lugar o rendimento escolar positivo e, consequentemente, o sucesso escolar, ou não?

Aqui vêem-se reflectidas as diferenças existentes naquilo que são efectivamente as categorias de sucesso escolar e sucesso educativo, corroboradas pela conceptualização desenvolvida por Perrenoud (2003) na sua obra, a qual reflecte a actualidade da problemática educativa e escolar.

\section{Conclusões}

Os alunos com dificuldades de aprendizagem apresentam índices mais elevados na componente sócio-demográfica representada pelas retenções de ano escolar, frequência de ano escolar e idade cronológica; índice inferior na componente educativo-pedagógica, reportada ao rendimento escolar nas diversas unidades curriculares, e na componente psicológica referente à aptidão cognitiva para aprender e à motivação para estudar, quando comparados a alunos sem dificuldades de aprendizagem. As diferenças são estatisticamente significativas.

O rendimento escolar positivo não depende exclusivamente da aptidão cognitiva para aprender, sendo que não são raras as situações de rendimento escolar negativo determinado predominantemente pelo baixo grau de motivação para estudar.

$O$ rendimento escolar negativo em alunos com dificuldades de aprendizagem maioritariamente tem o selo do insuficiente desenvolvimento da aptidão para aprender, sendo que o baixo índice de motivação para estudar reforça o agravamento negativo do rendimento escolar. Particularmente há alunos deste contingente que tendo fracas aptidões para aprender, mas níveis razoáveis de motivação para estudar e de dedicação ao processo de estudo conseguem alcançar resultados satisfatórios no rendimento escolar, ainda que sofríveis. Ao contrário, nos alunos sem dificuldades de aprendizagem o fraco e negativo rendimento escolar é predominantemente causado pelo muito fraco índice de motivação e de dedicação ao estudo e nunca, ou quase nunca, por falta de capacidade para aprender.

As frequentes situações de insucesso vividas pelos alunos provocam reduções apreciáveis na auto-estima e auto-conceito, sendo que, em consequência do desconforto interior experimentado, esses alunos tenderão a evitar executar as tarefas com a finalidade de não serem julgados pelas suas verdadeiras aptidões, mas pela sua motivação negativa. Comportamento que obriga os outros a transferir a atribuição causal do insucesso da incapacidade do aluno para a sua falta de interesse e motivação. Desta forma o aluno assegura a defesa de integridade do seu Ego; obviamente na sua perspectiva.

Por fim, conclui-se que futuramente poderiam adquirir nível superior de oportunidade e actualidade investigações em que o mesmo objecto, constituído pelo mesmo contingente de alunos, fosse avaliado, no plano das atribuições de causalidade, simultaneamente pelo próprio aluno e por vários tipos de observadores - pais, pares, familiares e professores.

\section{Referências}

Adelman, H. S. (1971). The not so specific learning disability population. Exceptional Children, 37, 528-533.

Almeida, L. S., Miranda, L., \& Guisande, M. A. (2008). Atribuições causais para o sucesso e fracasso escolares. Estudos de Psicologia. Campinas, 25 (2), 169-176.

Arends, R. I. (1995). Aprender a ensinar. Lisboa: McGraw-Hill.

Associação de Psiquiatria Americana [APA] (1980). Manual de Diagnóstico e Estatística de Transtornos Mentais (DSM - III). Brasil: Artes Médicas Sul.

Associação de Psiquiatria Americana [APA] (1996). Manual de Diagnóstico e Estatística de Transtornos Mentais(DSM - IV). Lisboa: Climepsi Editores.

Benavente, A. (1990). Insucesso escolar no contexto português abordagens, concepções e políticas. Análise Social, vol. 25 (108109), $\left(4^{\circ}\right.$ e $\left.5^{\circ}\right), 715-733$.

Binet, A., \& Simon, T. (1916). The intelligence of the feebleminded. Baltimore: Williams \& Wilkins.

Bos, C.,\& Vaughn, S. (1988). Strategies for teaching students with learning and behavior problems. Boston: Allyn \& Bacon.

Brophy, J. (1988). On motivating students. Em D. Berliner, \& B. Rosenshine (Orgs.), Talks to teachers (pp. 201 - 245).New York: Random House.

Bzuneck, J. A. (2009). A motivação do aluno: aspectos introdutórios. Em E. Boruchovitch, \& J. A. Bzuneck (Orgs.). A motivação do aluno: contribuições da psicologia contemporânea ( $4^{\mathrm{a}}$ ed.). Petropólis, RJ: Vozes.

Carroll, J. B. (1992). Human cognitive abilities. New York: Cambridge University Press.

Cattell, R. B. (1971). Abilities: their structure, growth and action. Boston: Houghton Mifflin.

Fonseca, V. (2004). Dificuldades de aprendizagem. Lisboa: Âncora Editora. 
Forgiarini, S. A. B.,\& Silva, J. C. (2008). Fracasso escolar no contexto de escola pública: entre mitos e realidades. Recuperado em: 22 mai. 2014. Disponível: http//www.diaadiaeducacao.pr.gov.br/ portals/pde/arquivos/369-4.pdf

Gagné, M.,\& Deci, E. L. (2005). Self-determination theory and work motivation. Journal of Organizational Behavior, Malden, 26, 331 -362 .

Graham, S. (1996). How causal beliefs influence the academic and social motivation of African-American children. Em G. G. Brannigan (Org.), The enlightened educator: research adventures in the schools(pp. 111 - 126). New York: McGraw-Hill.

Guimarães, S. E. R. (2001). Motivação intrínseca, extrínseca e o uso de recompensas em sala de aula. Em J. A. Bzuneck, \& E. Boruchovictch (Orgs.), A motivação do aluno: contribuições da psicologia contemporânea (Vol. 1). Petropólis: Vozes.

Guimarães, S. E. R., \& Boruchovitch, E. (2004). O estilo motivacional do professor e a motivação intrínseca dos estudantes: uma perspective da teoria da autodeterminação. Psicologia: ReflexãoCrítica,17(2), 143-150.

Horn, J. L. (1976). Human abilities: a review of research and theory in the early 1970`s. Annual Review of Psychology,27, 437-485.

Huertas, J. A., \& Agudo, R. (2003). Concepciones de los estudantes universitarios sobre la motivación. Em C. Monereo, \& J. I. Pozo (Orgs.), La universidade ante la nueva cultura educativa: enseñary aprender para la autonomia. Madrid: Síntesis.

Kelly, G. (1995). A theory of personality: the psychology of personal constructs. New York: Norton.

Kember, D. (1997). A reconceptualization of the research into university academic conceptions of learning. Learning and Instruction, 7(3), $225-275$.

Leal, E. A., Miranda, G. J., \& Carmo, C. R. S. (2013). Teoria da autodeterminação: uma análise da motivação dos estudantes do curso de ciências contábeis. Revista Contabilidade \& Finanças USP, 24(62), 162-173. Universidade de São Paulo, Brasil.

Lira, G. D. (2008). Fracasso escolar: visão de professores das séries iniciais do ensino fundamental da cidade de Cajazeiras PB. Tese de mestrado, Universidade Lusófona de Humanidades e Tecnologias, Lisboa-Portugal.

Máiquez, M. L., Rodrigo, M. J., Capote, C., \& Vermaes, I. (2000). Aprender en la vida cotidiana. Um programa experiencial.Madrid: Visor.

Martini, M. L., \& Prette, Z. A. P. Del (2005). Atribuições de causalidade e afectividade de alunos de alto e baixo desempenho académico em situações de sucesso e de fracasso escolar. Interamerican Journal of Psychology, 39(3), 355-368.
Mestres, M. M., \& Goñi, J. O. (2000).Factores psicológicos implicados na aprendizagem escolar: as características individuais. Em Salvador C. C., Alemany, I. G., Martí, E., Majós, T. M., Mestres, M. M., Goñi, J. O., Gallart, I. S., \& Giménez, E. V. (Orgs.),Psicologia do Ensino. Porto Alegre: Artmed.

National Joint Committee of Learning Disabilities [NJCLD] (1988). Definitions, Letter to Members Organization. Washington.

Nogueira, M. A. (1991). Trajectórias escolares, estratégias culturais e classes sociais. Teoria e Educação,n. 3. Porto Alegre.

Nogueira, M. A. (1995). Convertidos e Oblatos - Um exame da relação de Classes médias/Escolas na obra de Pierre Bourdieu. Mimeo.

Norenzayan, A., Choi, I.,\&Nisbett, R. E. (1999). Eastern and western perceptions of causality for social behavior: lay theories about personalities and social situations. EmD. Prentice, \& D. Miller (Orgs.),Cultural divides: understanding and overcoming group conflict.New York: Sage.

Pérez Echevarría, M. P., Mateos, M. M., Pozo, J. I., \& Scheuer, N. (2001). En busca del constructivismo perdido: concepciones implícitas sobre el aprendizage. Estudios de Psicología,22(2), 155 $-173$.

Perrenoud, P. (2003). Sucesso na escola: só o currículo, nada mais que o currículo! Cadernos de Pesquisa, n. 119, 7-26.

Piaget, J. (1978). O nascimento da inteligência da criança(3a ed.). Rio de Janeiro: Zahar Editores.

Pozo, J. I., Scheuer, N., Pérez Echevarría, M. P.,\& Mateos, M. (1999). El cambio de las concepciones de los professores sobre el aprendizage. EmJ. M. Sanchez, A. Onorbe, \& I. Bustamante (Orgs.), Educación Científica. Madrid: Ediciones de la Universidad de Alcalá.

Pozo, J. I. (2005). Aquisição de conhecimento. Porto Alegre: Artmed.

Reeve, J., Deci, E. L., \& Ryan, R. M. (2004). Self-determination theory. A dialectical framework for understand sociocultural influences on student motivation. Em D. M. Mclnerney, \& S. Van Etten (Orgs.), Big theories revisited (pp. 31 - 60). Connecticut: Age Publishing.

Rodrigo, M. J., Rodriguez, A., \& Marrero, J. (Orgs.) (1993). Las teorias implícitas: una aproximación al conocimiento cotidiano. Madrid: Visor.

Roazzi, A.,\& Almeida, L. S. (1988). Insucesso escolar: insucesso do aluno ou insucesso do sistema escolar? Revista Portuguesa de Educação, 1(2), 53-60.

Rothstein-Fisch, C., \& Trumbull, E. (2008). Managing diverse classroms: how to buid on students ' cultural strengths. Alexandria, VA: ASCD. 
Ryan, R. M., \& Deci, E. L. (2007). Active human nature: Selfdeterminatin theory and promotion ans maintenance of sport, exercice and health. Em M. S. Hagger, \& N. L. D. Chetzisarantis (Orgs),Intrinsec and extrinsec motivation and self-determination in exercise and sport (Vol. 1, pp. 1-19. Champain: Human Kinetics.

Siqueira, L. G. G.,\& Wechsler, S. M. (2006).Motivação para a aprendizagem escolar: possibilidades de medida. Avaliação Psicológica.5(1), pp. 3-21.

Sprinthall, N. A.,\&Sprinthall, R. C. (1997). Psicologia educacional. Lisboa: McGraw-Hill.

Sternberg, R. J. (1988). Inteligencia humana (Vol. 4). Barcelona: Paidós.

Tapia, J. A. (1991). Motivación y aprendizaje en el aula. Madrid: Santillana.

Trumbull, E., \& Rothstein-Fisch, C. (2011).The intersection of culture and achievement motivation. The School Community Journal, 21(2).

Weiner, B. (1984). Principles for a theory of student motivation and their application within an attributional framework. Em R. Ames, \&
C. Ames (Orgs), Research on motivation in education (Vol. 1, pp. 15-38). New York: Academic Press.

Weiner, B. (1986). Attribucional theory of motivation and emotion. New York: Springer.

Weiner, B. (1994). Ability versus effort revisited: The moral determinants of achievement evaluation an achievement as a moral system. Educational Psychologist, 29, 163-172.

Weiner, B. (1994). Integration social and persons theories of achievement striving. Review of Educational Research, 64, 557575.

Weiner, B. (2000). Interpersonal theories of motivation from an attributional perspective. Educational Psychology Review, v. 12, n. 1, pp. 1 - 14. New Cork.

Weiner, B. (2004). Attribution theory revisited: transforming cultural plurality into theoretical unity. Em D. M. Mclnerney, \& S. Van Etten (Orgs),Bigteories revisited(pp. 13-29). Connecticut: Age Publishing.

Woolfolk, A. E. (2000). Psicologia da Educação (7 $7^{\mathrm{a}}$ ed.). Porto Alegre: Artmed.

\section{Sobre o autor}

Fernando Oliveira Pereira (fopereira@sapo.pt)

Ph. Doctor em Psicologia. Professor Coordenador da Escola Superior de Educação Almeida Garrett / Universidade Lusófona de Lisboa, Lisboa - Portugal 